Portland State University

PDXScholar

$12-2021$

\title{
The Semiconductor Shortage: an Analysis of Potential and Ongoing Remediation Efforts and their Implications on the Industry \& Macroeconomy
}

Carter Young

Portland State University

Follow this and additional works at: https://pdxscholar.library.pdx.edu/honorstheses

Part of the Operations and Supply Chain Management Commons

Let us know how access to this document benefits you.

Recommended Citation

Young, Carter, "The Semiconductor Shortage: an Analysis of Potential and Ongoing Remediation Efforts and their Implications on the Industry \& Macroeconomy" (2021). University Honors Theses. Paper 1162. https://doi.org/10.15760/honors. 1180

This Thesis is brought to you for free and open access. It has been accepted for inclusion in University Honors Theses by an authorized administrator of PDXScholar. Please contact us if we can make this document more accessible: pdxscholar@pdx.edu. 
The Semiconductor Shortage:

An Analysis of Potential and Ongoing Remediation Efforts and their Implications on the Industry \& Macroeconomy

by

Carter Young

\begin{abstract}
An undergraduate honors thesis submitted in partial fulfillment of the requirements for the degree of

Bachelor of Science

in

University Honors

and

Accounting and Finance
\end{abstract}

Thesis Adviser

Ted Khoury

Portland State University 


\section{Abstract}

In recent months, the health of the macroeconomy has suffered due to logistical issues, inflation, and the labor market. Specifically, supply-side shocks within the semiconductor industry have dramatically affected firms' ability to produce chipsets. The resulting destabilization is felt across innumerable downstream sectors which rely on these products for implementation into their own finished goods. This paper examines the exact impacts of these recent developments within the semiconductor industry, utilizing what-if and historical analysis to gauge how logistical issues, inflation, and increased capital expenditures will financially impact both firms within the industry and those which depend on their production. Additionally, it will utilize general hypothetical scenarios to discover what firms can do, if anything, to abate the current shortage and assuage concerns regarding future issues. The most common financial decisions, such as the allocation of funds for capital expenditure and research \& development, are analyzed in-depth to ascertain how budgeting for these items must be shifted in response to widespread component and production shortages. Given vertical integration within this industry, the response of any one firm will differ greatly, as will their interactions with the supply chain. However, generalizable analysis can provide context for firm decisions regardless of the current health of the industry, leading to a more rigorous and logical examination of trends affecting both this market and the macroeconomy. 


\section{Introduction}

In recent months, significant macroeconomic and political trends have dramatically affected equity markets. The ongoing pandemic, the labor market's corresponding road to recovery, and various concerns regarding supply chain issues and inflation have all caused severe volatility in numerous markets.

Specifically, the information technology sector has been severely weakened by these developments. The sector has performed feebly year-to-date, only recently rebounding and showing signs of life. ${ }^{1}$ This is in stark contrast to how the industry fared at the beginning of the pandemic in March 2020. Most companies in the industry did well throughout the beginning of the pandemic as other sectors and industries relied on technological hardware, services, and digitization to enable remote learning and working. Meanwhile, consumer-related sectors, healthcare, and energy all struggled significantly more.

Now that the economy is slowly recovering, analysts expect information technology companies will be unable to match last year's high growth. Conversely, as individuals gain the ability to spend freely, consumer spending on both staples and discretionary goods will increase exponentially. Moreover, supply chain issues caused by low levels of manufacturing during the pandemic continue to impact the sector holistically, as well as other industries which depend on their production. Additionally, these supply chain issues have direct economic impact in the form of prolonging already severe inflation. On September $30^{\text {th }}, 2021$, Federal Reserve chairman Jerome Powell noted that factory shutdowns caused by supply issues directly boost inflation due to the limited production of finished goods. Unfortunately, monetary and fiscal policy is relatively powerless to remedy these supply-side shocks, only the direct effects of these 
shortages can be mitigated. ${ }^{2}$ While these supply chain issues affect nearly every industry, their impacts on the semiconductor industry have cascaded to devastate dozens of other sectors and are therefore exceedingly disruptive.

The logistical obstacles the semiconductor industry faces coincide, unfortunately, with numerous other issues. Primarily, heightened demand has led to the manufacturing, design, and retail of semiconductors becoming increasingly attractive, thereby boosting competition dramatically. The resulting shifts in market share have lowered marginal returns for nearly all firms, motivating many to undercut competitors by lowering the prices of their products. Coupled with inflation and a need for more rapid innovation, this altogether results in quicker product cycles but a stifled ability to manufacture the required quantity of products. Of course, because of lower unit prices and less production, returns lower even more dramatically. As a result, the amount of available funds that manufacturing and design firms have to reinvest in and improve their capital assets is drastically reduced, prolonging supply chain issues, financial hardship, and macroeconomic inflation. This most severely impacts companies like Nvidia Corp., Intel Co., and American Micro Devices. These firms specialize in the design and retail of chips, but not always their manufacturing. Meanwhile, manufacturing firms like Taiwan Semiconductor Manufacturing Company and GlobalFoundries are maxing out capacity and reinvesting heavily in production efforts to catch more downstream revenue.

This thesis will attempt to examine the exact impacts of these recent developments within the semiconductor industry, utilizing what-if and historical analysis to gauge how logistical issues, inflation, and increased capital expenditures will financially impact both firms within the industry and those which depend on their production. Additionally, it will utilize general hypothetical scenarios to discover what firms can do, if anything, to abate the current shortage 
and assuage concerns regarding future issues. While the utilization of pro-forma financial statements and DCF valuation techniques appears logical, the analytical models used to gauge the severity of supply chain issues within this industry focus mostly on technical data. Therefore, estimating the quantitative economic effect of supply chain changes or technical development becomes exceedingly difficult.

\section{Semiconductor Shortage and its Implications}

In the early 2000s, the proliferation of the internet and the increasing popularity of PCs boosted demand for semiconductors and the products they constituted dramatically. Ethernet equipment, network processors, and other devices all rely heavily on the production of semiconductors. ${ }^{3}$ Firms now utilize microprocessors for a wide array of applications. As technological innovation intensifies, demand has rapidly increased. According to Price Waterhouse Coopers' 2018 forecast, semiconductor market growth was estimated to increase by $94 \%$ between 2016 and 2022, with the logic and memory segments seeing the largest growth (see Fig. 1).

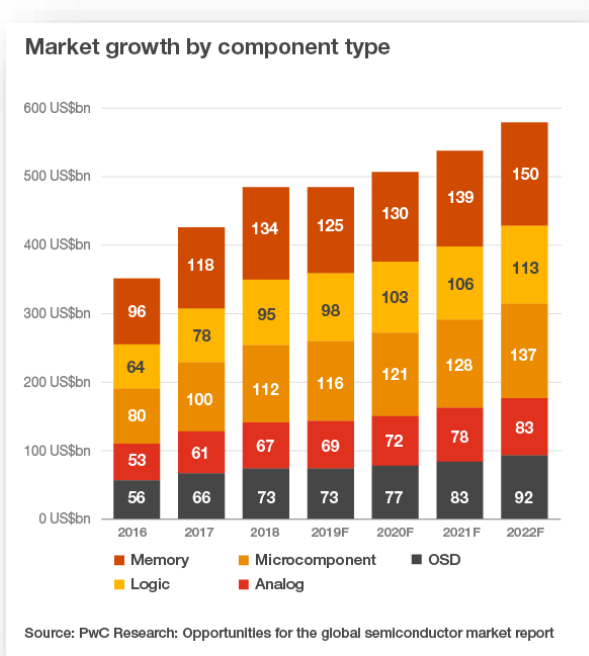

Figure 1: Semiconductor Market Growth by Segment (source: PwC Research) 
This significant growth of the semiconductor market is attributable directly to the proliferation of artificial intelligence in vehicles, an increased emphasis on immersive technology, and the continued integration of semiconductors into everyday products like toothbrushes and scales. In the automotive market, semiconductors have allowed firms to make their vehicles safer and more efficient, but their implementation coupled with the prolonged effects of the COVID-19 pandemic has drastically slowed the production of some cars. ${ }^{4}$

During the first months of the pandemic, automakers reacted to global lockdowns by deprioritizing production and severely decreasing their chip purchases. In response to this, semiconductor retailers shifted their focus to producing PCs and mobile workstations to support workers who had to remain at home and enable remote healthcare. However, automotive firms' demand for semiconductors recovered much faster than chip manufacturers had estimated (see Fig. 2). Unfortunately for much of the market, chip manufacturers historically take a very

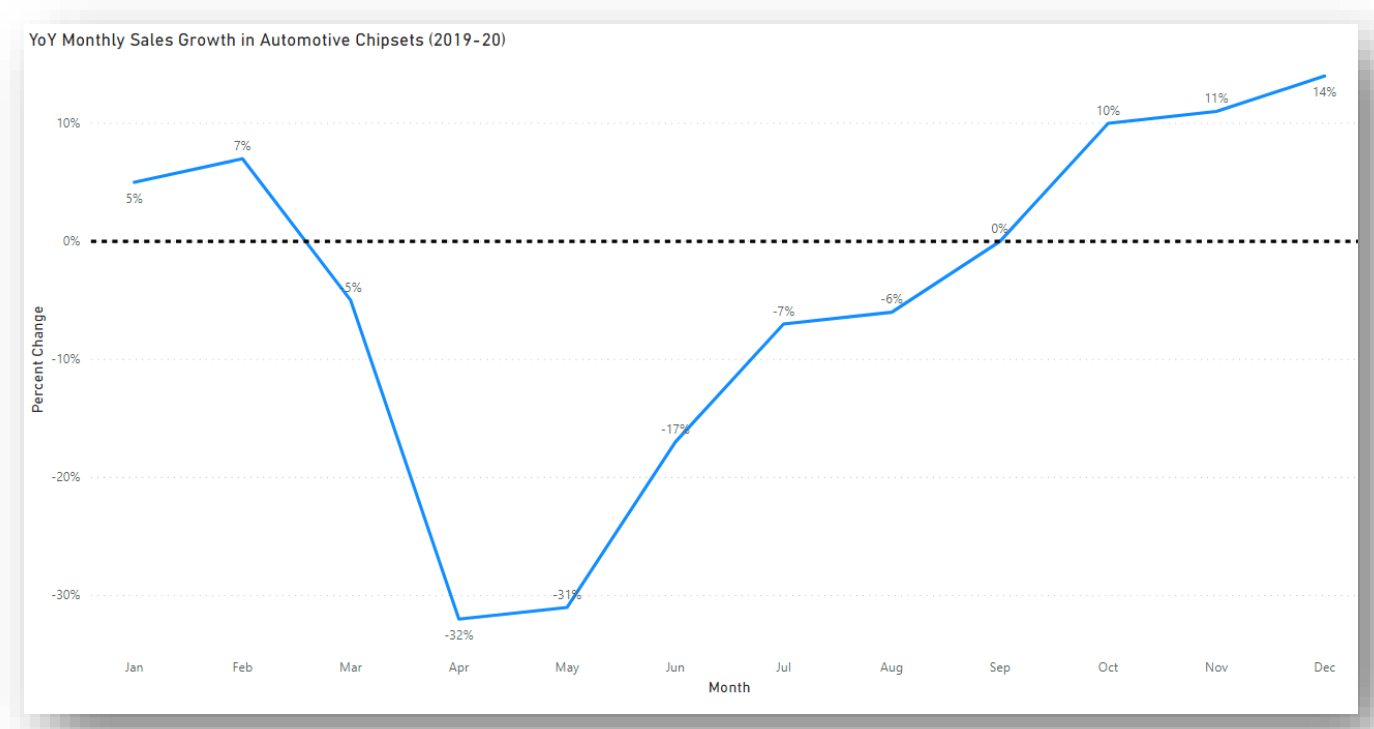

Figure 2: YoY Monthly Sales Growth in Automotive Chipsets 2019-20 (source: World Semiconductor Trade Statistics Bluebook Sales Data. 2020-2019) ${ }^{5}$ 
long time to ramp up production. This quality is made worse by the fact that many firms are expanding production simultaneously, pinching the overall supply of raw materials and resources (see Fig. 3). Specifically, manufacturers suffer the effects of reduced supplies of glass substrates and Ajinomoto Build-up Film (ABF), severely restraining the production of GPUs and CPUs. ${ }^{6}$

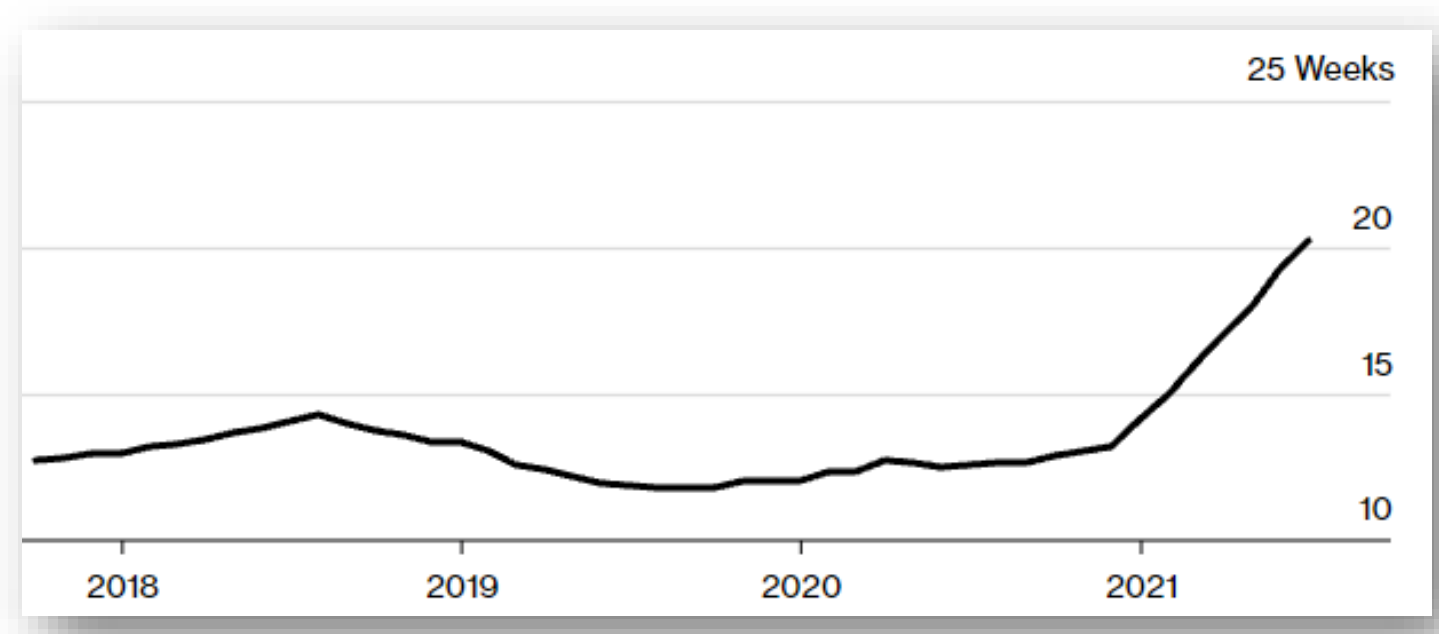

Figure 3: Chip lead times 2018-21 (source: Bloomberg.com) ${ }^{7}$

Due to these increasing lead times, the semiconductor industry and its economics can be viewed as a lagging indicator. Depending upon the willingness of individuals to spend money on consumer good that utilize chipsets, firms within the industry see highly fluctuating profitability. Because of this inextricable tie to the macroeconomy, the industry is highly volatile, and booms of demand follow busts with remarkable rapidity. Due to shifting prioritization as the pandemic fades, demand for semiconductors has revived suddenly and intensely. While the pandemic introduces unsystematic and irregular variables, conditions are unpredictable even during normal times. For instance, three of the most recent downturns in the industry can be directly attributed to oil shocks in 1975, 1982, and 1991 (see Fig. 3). ${ }^{7}$ Meanwhile, the Asian recessionary crisis of 1998 and the com bubble also led to considerable turmoil within the industry. 


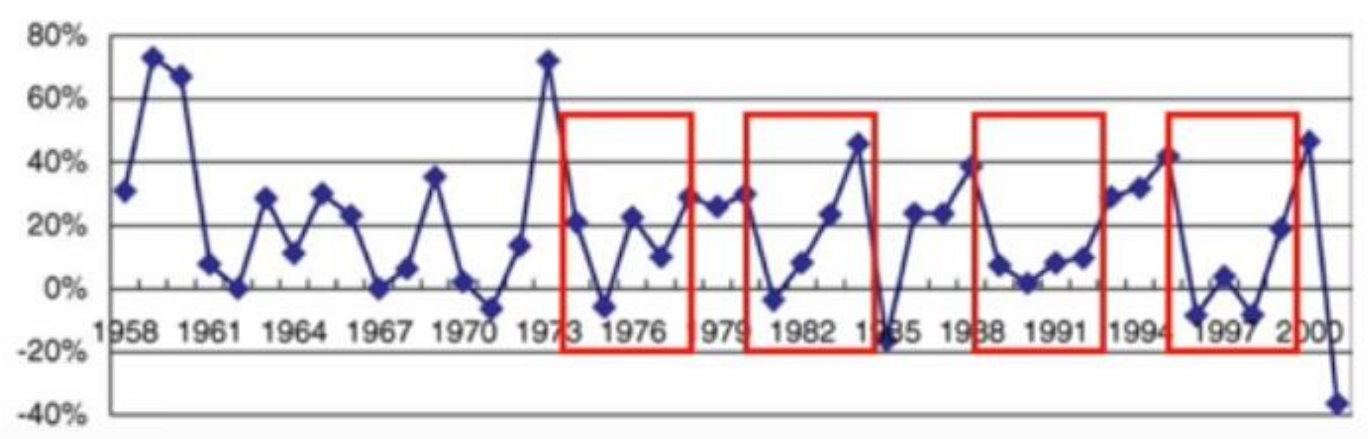

Fig. 1. Worldwide semiconductor shipments growth (1958-2001). Source: World Semiconductor Trade Statistics (WSTS).

Figure 3: Semiconductor shipments compared to macroeconomic recessions (source: World Semiconductor Trade Statistics)

The sector's strong ties to the macroeconomy are exactly why a shortage is currently occurring. In March 2020, semiconductor firms reacted to the crash of the stock market by deprioritizing production, assuming demand for consumer goods would rapidly decline alongside the economy at large (see Fig. 4). ${ }^{8}$ It is paramount for these firms to cut expenses and survive these crashes, as the fabs and equipment necessary to produce chipsets come with high fixed costs and overhead. However, the stimulus packages dispersed in response to the pandemic led to the economy recovering rapidly. As perceived demand fell, then consequently surged, fabs needed to quickly raise capacity to meet recovering consumer good demand.

Importantly, the high fixed costs of fabs and factories require manufacturing firms to continue producing as much as possible once capital investments are made. The priority for these businesses will always be to raise whatever profit they can to amortize their high fixed costs. In the current environment, demand is high enough for these firms to earn returns. However, given 


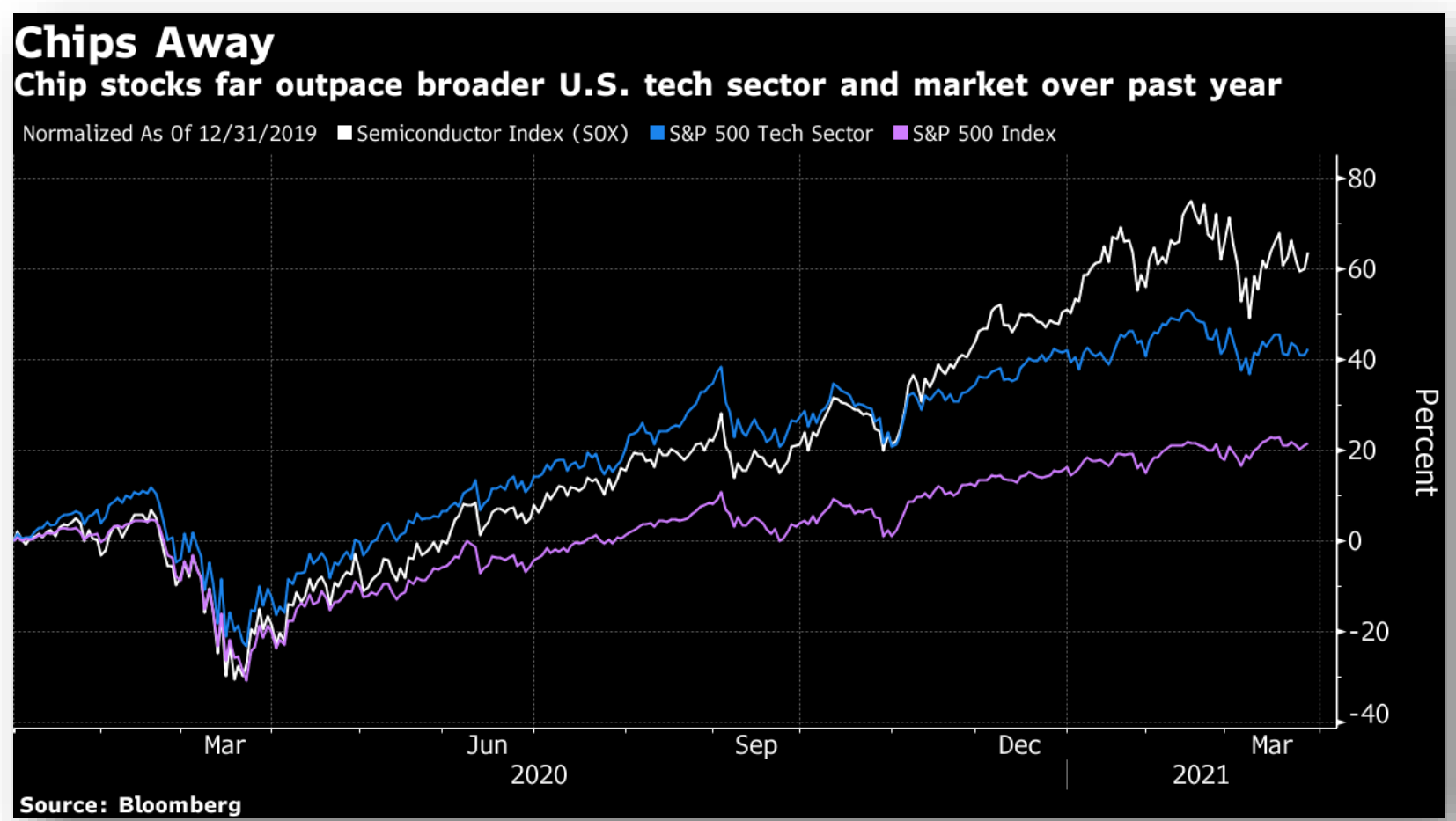

Figure 4: Semiconductor Index compared to S\&P500 and S\&P500 Tech Indices (source:

Bloomberg.com)

a glut in supply, they are forced to sell chips at what is effectively a survival cost. Moreover, the simultaneous construction of fabs by numerous firms is characterized by supply chain constraints and demand imbalances. Numerous foundries will fight over access to the best construction and engineering talent as these facilities ramp up. These trends in capacity, just as much as demand, are the determinants of the semiconductor industry's business cycle.

As explained above, the semiconductor business cycle and the shocks it experiences are determined largely by capacity. While the current concern of the market is that of a severe and sudden chip shortage, it may just as quickly develop into overproduction depending on the state of the economy. Because shortages have so badly scarred the industry, foundries and fabs such as Intel and TSMC are becoming more willing to raise the inventory levels of certain 
components and end products. Additionally, because supply chains can be thrown into disarray by one missed shipment, just-in-time inventory methods are no longer viable for the industry. Due to demand and supply imbalances, chip manufacturers have rapidly shifted priority to constructing new fabs and factories to boost capacity. Firms such as AMD and Apple, two of TSMC's largest customers, have had severe issues with product rollouts resulting from the current lack of capacity. Missing these launch cycles or releasing an obsolete chipset can have dire consequences in such a competitive industry. Companies like these have proper precautions to dilute the impact of these shortages to their bottom line, and so while the negative effects are limited, they are non-zero. ${ }^{9}$

The more difficult and severe issue for these companies is forecasting when capacity will be able to meet current demand, and whether that demand will persist. End consumers do not directly purchase semiconductors, but the finished goods they contribute towards. This degree of separation adds a layer of complexity to forecasting where supply and demand will intersect, an issue exasperated by heightening lead times. Moreover, this calculation must consider the evershortening shelf life of chipsets. As the industry grows more competitive, the rate at which firms must roll out and refresh their product line is growing perpetually shorter. Because fabless firms are the most product-oriented and technologically intensive part of this industry, the nuanced and purposeful use of their capital assets is the most intriguing and relevant. Due to the degree of their capital investments and the necessity of consistent product rollouts, fabless firms must prioritize securing stock and ensuring capacity is high enough to meet their demands. While it is simple for speculators and investors to demand a higher degree of investments go towards increasing capacity, the unpredictability of the business cycle and the cost of these facilities precludes snap judgment and can drastically extend shortages. It is estimated that a state-of-the 
art fab built in the United States has an average cost of $\$ 3 \mathrm{~B} .{ }^{10}$ Given intense fluctuations in the industry's wellbeing as seen in figure 4, outlaying this money with no insight to the industry's likely cycles may prove disastrous.

Therefore, estimating the trends the industry will go through and to what degree they will affect demand is exceedingly important. To do this, trade journals and industry experts consider two disparate analyses. First, many experts judge the industry to follow a traditional cycle with its troughs and peaks lasting roughly five years. However, the growth experienced during those peaks varied widely. ${ }^{11}$ This degree of analysis alone cannot explain why, from 1970 to 1995 , the industry grew at a compound annual rate of 16\%, while from 1995 to 2000, it grew at an annual rate of only $6 \% .^{12}$

Meanwhile, the second traditional method of analysis incorporates what downstream and macroeconomic effects impact demand for semiconductors. As mentioned above, major recessions are enough to dramatically affect demand. Additionally, though, an oversupply of chips can effectively crash the industry due to imbalances. If intermediate consumers such as automakers and computer component manufacturers have too large of inventories, their demand the following year will necessarily struggle to match the consistent stream of chips that manufacturers produce. Because the fundamental structure of semiconductor manufacturers incentivizes them to produce as many chips as possible to lower the impact of high fixed costs, just one year of this imbalance is enough to damage firms and the industry for years. ${ }^{13}$ According to Liu's 2005 article, a block exogeneity test shows that $24.678 \%$ of the industry's global variation in revenue is due to the efficacy of inventory management. Meanwhile, the number of semiconductors produced by both U.S. firms and global firms accounts for roughly $34 \%$ of the industry's global revenue variation. ${ }^{14}$ These empirical findings are consistent with the basic 
functions and characteristics of the semiconductor industry. With high degrees of R\&D and capital investment, companies with short product cycles and a demand for manageable lead times, many manufacturers focus on expanding capacity as quickly as possible by increasing efficiency and advancing the sophistication of their machinery. This, to many, may seem the only way to guarantee growth in market share.

Given these characteristics, managing the supply of semiconductors and finding where production and forecasted demand will coincide is the primary solution for developing consistent business cycles. Troughs come about due to regular overcapacity across the industry, leading to bulging inventories which oversaturate the market and incentivize downstream customers to stop buying chips. In turn, the largest semiconductor manufacturers can continue selling whatever paltry amount the market still necessitates at their survival cost, just enough to cover costs. Meanwhile, smaller and newer firms are forced to match that low sales price which, in most cases, cannot sufficiently amortize their higher and less refined cost systems, leading to acquisition or outright liquidation. Most often, this results in a degree of technology transfer and competition consequently suffers. Subsequently, the cycle continues. Because larger firms face relatively little consequences, their prognostications regarding the positive impacts of capacity expansion outweighs the negative implications of oversupply, feeding into the dramatic fluctuations that characterize the industry.

\section{Capital Investment and Asset Management in the Semiconductor Industry}

To assuage the effects of chip shortages and a lack of capacity due to sudden demand, chip foundries and manufacturers have intensely increased their investment in new fabs and factories. 
Over three years, TSMC plans to spend over $\$ 100 \mathrm{~B}$ to expand capacity and build new fabs in Arizona, an unprecedented step for the Taiwanese company. ${ }^{15}$ Intel has vowed to match this with a \$20B investment in their own Arizonan fabs. ${ }^{16}$ While these investments are significant and implicative for the future of semiconductor manufacturing capacity, the actions of individual fabless manufacturers are just as profound. Although capacity and its relationship to demand has been proven to be the most significant determinant of the semiconductor industry's business cycle, the degree to which fabless manufacturers invest in new and diverse sets of equipment also dictates the state of the industry and its firms.

The financial performance of fabless manufacturers relies heavily on how efficient they can make their processes while still emphasizing technological advancement. The hypercompetitive and increasingly complex nature of the industry necessitates that these firms prioritize new product development (NPD) via both technological depth and breadth. ${ }^{17}$ Due to the state of the industry, firms are now unable to rely on existing technologies as their growth driver. Instead, they must invest into making continual innovations and improvements to eke out more growth than competitors. Meanwhile, offering a wide array of products and solutions for customers ensures their mix is diversified and shielded against volatility, providing a path for consistent and growing profitability.

NPD requires numerous intentional business and financial decisions, chief among them being an efficient and realistic research and development process. This R\&D process and the consistent expansion of technological capability necessitates repeated investments in capital assets and infrastructure. The sophistication of these capital assets highly affect a firm's lead time and ability to change the industry's standards via technological advancement. ${ }^{18}$ Another key component of technological advancement is designing a product platform which makes fabless 
firms more efficient and reliable. To build economies of scale and make sufficient use of expensive capital equipment, firms ensure their product platforms are adaptable and fit for a variety of uses. The products derived from these platforms can be quickly adjusted based on demand while new technologies can be developed efficiently and accurately. This product differentiation can be used as a basis to enter new market segments and efficiently add growth to a company's portfolio. ${ }^{19}$

As identified above, the two most significant drivers of profitability and growth via innovation is a purposeful and strategic investment in efficient capital assets and product platforms. For technological-intensive firms, being able to iterate on past advancements with new, ground-breaking techniques is the most impactful intangible asset possible. Not only does it positively affect their financial performance, but it also bolsters their market share and supports the maintenance of their portion of that industry. Because fabless manufacturers are largely removed from the acquisition and supply of raw materials, these capital investments enable them to derive the maximum value from the supply chain. ${ }^{20}$

Because the market now must cater to highly diverse and unique needs depending on the customer, the development of rigorous and efficient product platforms becomes more expensive, and the process lengthier. Much like forecasting capacity, the construction of product platforms requires a certain amount of inference alongside competitive strategy. Additionally, these wagers on future trends are made riskier and more speculative by just how long it takes to ramp development of new platforms. A fabless manufacturer may make a bet regarding the future of the market which takes effect 5-7 years later, only for the market to have moved in an entirely different direction. ${ }^{21}$ However, accurate prognostication of future trends represents an incredible 
competitive advantage which can provide a firm with long-term growth opportunities, thereby enabling them to be even more speculative with their future development.

Just as important to a firm as their technological capability and product platforms is the efficiency of their innovations and the potential impacts they have. Measuring the efficiency of innovations made by a firm has historically been done using stochastic frontier analysis (SFA) or data envelopment analysis (DEA) to measure innovation based on inputs and outputs. ${ }^{22}$ SFA allows firms to analyze single output scenarios. It can be used to measure the use of financial resources, via cost and profit efficiency analysis, or be applied to more abstract cases, such as the efficiency and efficacy of R\&D. Conversely, DEA can account for numerous outputs and inputs since it is "non-parametric", meaning the data are not assumed to come from predefined models. ${ }^{23}$ While DEA excels at examining relationships between inputs and outputs, it fails to consider non-operational or unsystematic factors. Therefore, numerous stages must be implemented to form context. While traditional forms of DEA can be used for self-assessment, they are not capable of gauging a firm's impact on the industry or surrounding communities.

To be deemed successful, innovation must return real and quantifiable financial and technical benefits to a firm. Both inputs and outputs are variable dependent on the exact scenario, but inputs generally involve labor, capital expenditures, and in this case, patent management. Meanwhile, outputs would be represented by the sales or profits a firm enjoys, as well as the patent applications they file. In the semiconductor industry specifically, the degree of capital and talented labor personnel required to achieve adequate outputs increases exponentially. ${ }^{24}$

Importantly, the labor input catches both lab technicians who help manufacture chips, as well as researchers and other personnel involved in $R \& D$ and associated activities. Additionally, due to the competitiveness of the industry and the importance of unique products, patent 
management and the associated degree of intellectual capital a firm has is essential to consider. ${ }^{25}$ Outputs for this model are comprised of sales and patents. While patents are the most important and direct indicator of innovation output, the profitability of the firm depends on whether the sales generated from pre-existing innovations outweigh the capital expenditures and labor costs a firm creates today. Importantly, not all innovations are patentable, or the ability to patent them may fluctuate according to legislature. And while patent applications are paramount when advancing technologically, their value to the business is accomplished only through commercialization. The ability of a firm to iterate on past technology entirely depends on previous innovations achieving commercial success. Therefore, the sales and profits generated from innovation via development is the most appropriate indicator for economic viability. The degree of temporal separation between inputs and outputs is also exceedingly important to consider. The semiconductor industry experiences rapid and dramatic levels of technological iteration according to Moore's Law. Because of this, the time lag between inputs and outputs is generally accepted as just one year, much lower than other industries. ${ }^{26}$ To remain viable within the industry, a firm must ensure that their innovation is done efficiently by using a combination of in-depth forecasting and DEA.

It has been established that to be performant, both technologically and economically, a fabless firm must consistently roll out new products and design product platforms which are efficient, scaling, and multi-use. All these targets must be accomplished within an exceptionally narrow time frame, quick enough to either set the pace of the industry or match competitors' cadence, while simultaneously ensuring that meaningful technical advancements have been made. While the exact relationships between economic fluctuations and innovative 
breakthroughs is difficult to track, there is little doubt that a firm's ability to iterate on their base technologies will directly determine their degree of financial success.

Recent federal incentives for innovation in both China and the United States have spurred many researchers to examine exactly what effect technical advantages have on the business cycle and vice versa. Generally, there are two perspectives for when a business should innovate. Some argue that the relationship is countercyclical, meaning that a firm will hesitate to devote resources to $R \& D$ and associated activities when in a period of high production, and will only transition their resources once production slows. Alternatively, the procyclical hypothesis argues that periods of high production are the best time to begin product development. Because these periods are when firms can accurately estimate the degree of their cash inflows, they lend the most data and context to the decision-making bodies. ${ }^{27}$

For the semiconductor industry, the correlation between business cycle and technological iteration is blurred. As product cycles narrow, product development also becomes more rapid. Per year, any given firm will roll out 1-3 products per segment which have been developed over the course of 5-7 years. The advantage previous innovations have provided seldom last very long until competitors are able to render them obsolete or match them. This incentivizes firms to target the short boom period following product launches to begin exploring new conceptual breakthroughs and achieve competitive advantages, thereby following a procyclical model. ${ }^{28}$ The competitiveness within the industry and the short ramp times it necessitates ubiquitously impacts both the financial and technological decisions of firms.

While a major part of the current semiconductor shortage has to do with shifting quickly back to max production, the direst consequences of the shortage have to do with simple products, not technologically advanced ones. While a lower capacity for high-end chips drastically affects 
fabless firms, the health of the macroeconomy and downstream consumers is more accurately gauged by how effectively a firm can produce 10- or 14-nanometer chipsets. However, the demand of major fabless firms like Apple and AMD for performant, 5- or 7-nanometer chips outweighs the demand of downstream consumers for semiconductors used in everyday products. ${ }^{29}$ Because product platforms are often designed to be used for a diverse set of products, these sets of demand necessarily interfere. Thereby, the flow and supply of less complex, more ubiquitous chips is affected drastically by both capacity and raw material shortages.

Both innovation via product development and the expansion of overall production capacity can be suggested as ways to remediate the chip shortage. Ensuring that product platforms are efficient, that resources are used effectively to pursue innovations, and that research and development is done at an appropriate time in the business cycle are all ancillary but essential facets of shortage remediation. While these numerous financial and technical decisions are productive and can help firms to cope with shortages, the external dependencies within the industry are numerous and drastic, making it an exceedingly fragile ecosystem. Despite many interfirm solutions, the multi-faceted issues continue to elongate the shortage and individual firms can do very little but cushion themselves and wait. Whilst foundries like TSMC and Intel construct new facilities to increase capacity, the macroeconomic imbalances between constrained supply and ever-increasing demand continues to pressure every firm within the industry, as well as their direct consumers. However, the importance of the semiconductor industry to other sectors within the economy and to national security has prompted numerous world governments to involve themselves in these shortage concerns, assisting the firms financially and subsidizing their production. 


\section{Legislative Remediation and Subsidization}

Legislative actions and policy tinkering have been suggested as a method to remedy chip shortages and ensure that production resumes as soon as possible. Much of this discussion focuses on the domestic production within either the United States or Taiwan. Local companies such as Intel argue that the production of semiconductors within the United States is an essential aspect of national security. Since 2015, U.S. sales of semiconductors have increased by only $34.2 \%$, while sales by Chinese firms have increased by $83.25 \%$, with other regions also experiencing high increases in sales. (see Fig. 5) The catalyst for American subsidies within the industry came in May of 2020, only two months after the beginning of the pandemic.

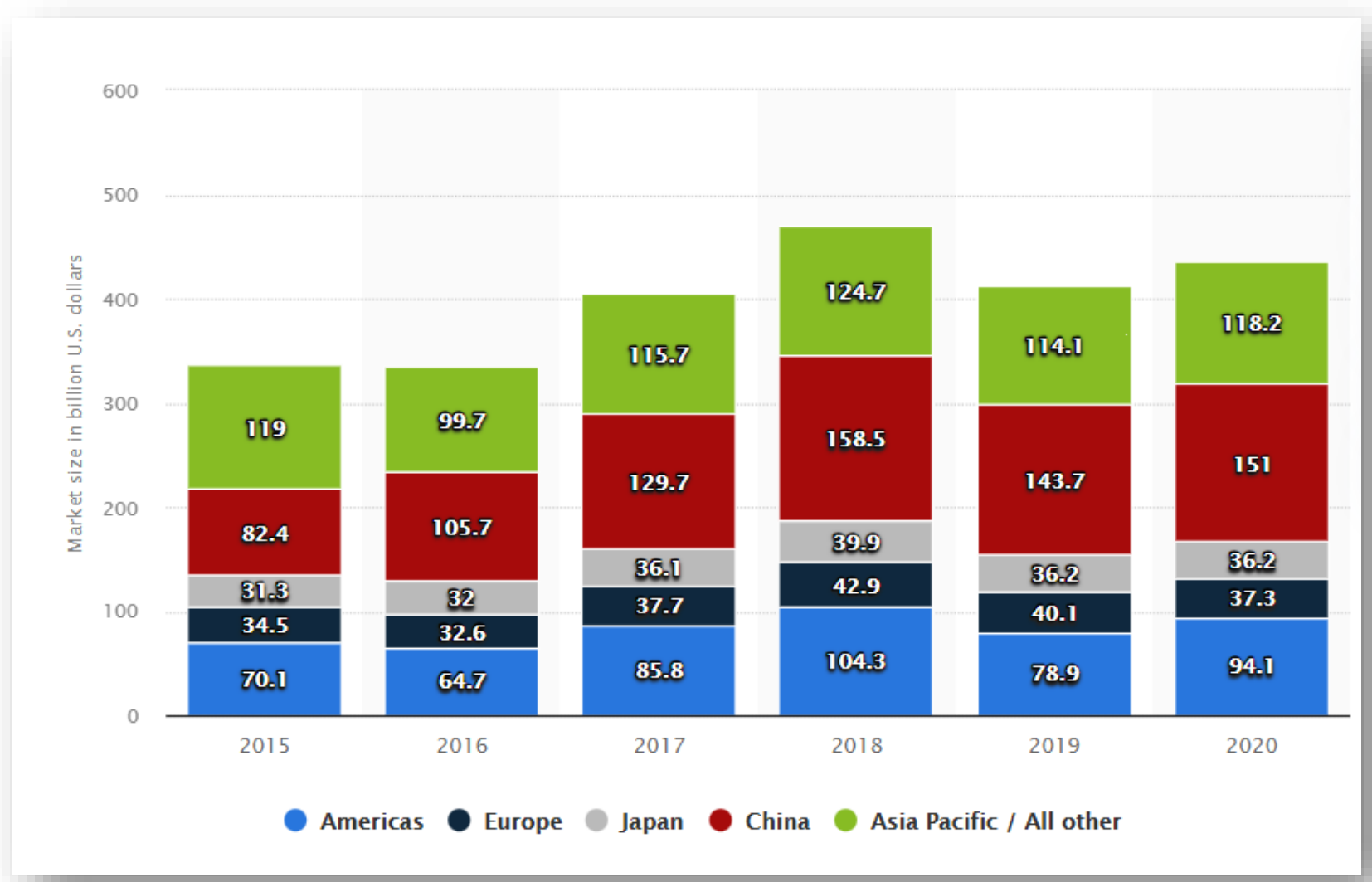

Figure 5: Global Semiconductor Sales by Region, 2015-20 (Source: statista.com) ${ }^{30}$ 
Following a trade embargo involving Chinese electronics producer Huawei, the Chinese firm SMIC received $\$ 2.2 \mathrm{~B}$ in subsidies from their government to amortize both firms' production costs. ${ }^{31}$ While subsidies to Chinese firms are common, the American government hesitates to interfere with the function of businesses, except in cases of extreme recessionary trends. However, as soon as a month after the announcement of these Chinese subsidies, American lawmakers were proposing that similar legislature be passed to support local manufacturers. ${ }^{32}$ As part of his infrastructure plan, President Biden proposed \$52B in subsidies meant for the semiconductor industry, a facet of his plan that enjoyed unique and unprecedented bipartisan support. $^{33}$

Given the incentives other nations offer to their firms, the demands of American semiconductor lobbyists have been reluctantly accepted by anti-economic interventionist politicians. Three quarters of the proposed funding would go directly to producers to construct new fabs so that they may expand their capacity. Of the $\$ 52 \mathrm{~B}, \$ 2 \mathrm{~B}$ is reserved to produce low complexity, cheaper semiconductors to be used by automotive manufacturers and other various consumers, which should boost the capacity of those most ubiquitous chips. Importantly, $\$ 10.5 \mathrm{~B}$ of that money would also be dedicated to fund research and technical development by various institutions, including a newly established National Semiconductor Technology Center, which would then be equipped with lithographic machines from ASML and other equipment manufacturing firms like LAM Research to develop new breakthroughs. In addition to this $\$ 10.5 \mathrm{~B}, \$ 81 \mathrm{~B}$ has been dedicated to fund the NSTC over the next five years. Much of this funding will go towards continued research into robotics, artificial intelligence, and machine learning. This signals a significant shift in the relationship between the U.S. legislative branch and the semiconductor industry. Additionally, in the last week of October 2021, the Biden 
Administration requested that major chip manufacturers submit data regarding their lead times, inventories, clients, and suppliers. With appropriate response, this information will help legislators assist the industry long-term with a well-structured and comprehensive bill.

While the shortage and COVID-19 pandemic may have catalyzed discussion regarding subsidies, Chinese firms and their economic relation to their government has introduced American legislators with an ultimatum. Chinese manufacturers' technology has already advanced to a point where both their capacity and expertise surpasses that of American firms. This has prompted companies like Apple and AMD to rely on them to an outsized degree. The possibility of American firms having no other option but to contract with Chinese manufacturers would present an existential problem to the operations and viability of all American consumers of semiconductors. Moreover, the Chinese government is infamously ambiguous regarding the term and degree of their subsidies, so while they may be providing support now, that can end unpredictably. Excessive reliance on such a fragile system would in turn jeopardize the global economy. While it will take years for these subsidies' effects to be felt by firms and consumers, it is a sure way to supplement both technological advancement and expanded capacity.

Although the implications of this increased capacity on the macroeconomy are difficult to foresee, the fragility of the supply chain is certain. This consistent instability must be examined and remediated, garnering a further analysis of the firms that constitute the industry and how they uniquely interact with the supply chain. While policy tinkering and legislation will largely determine the immediate recovery and viability of the industry, individual firms do have the capability to maximize their efficiency. So, while firm-level innovation and financial repositioning enables companies to establish inter-industry differentiation, those competitive advantages mean little when businesses struggle to rollout new products. 
Additionally, while improved capacity will greatly assist many firms in ramping production, it also pushes fabless firms to the periphery and incentivizes them to make material shifts in their business strategy. For example, since most of the funding proposed by President Biden in his Infrastructure Plan would go towards constructing fabs, fabless firms will receive marginal benefits. In fact, since Intel is the only manufacturer of considerable size in the United States, their direct competitors (e.g., AMD, Nvidia) will necessarily be at a disadvantage due to this legislation. Because of this, while the legislation is an appropriate response to an unprecedented shortage, its permanent establishment may centralize both financial and technical advantage within the industry for those who design and manufacture their chips in house. Instead, firms must focus on manipulating the ways they interact with the supply chain and examine what benefits could be gained from overhauling the industry's current habits. Because the three distinct segments of the industry- manufacturers, retailers, and equipment producers- all participate uniquely, further analysis of what the supply chain and shortage mean to them is necessary for future remediation and value maximization.

\section{Industry Segment Analysis and the Efficient Supply Chain}

There are three principal stages of semiconductor production, with design being a prerequisite: wafer fabrication and probe, assembly, and back-end operations. Due primarily to high capital expenditure and infrastructure costs, the semiconductor industry is uniquely segmented and specialized, meaning the supply chain is both integrated but distinct. In recent years especially, vertically integrated firms specializing in one function of production have been able to avoid the risks associated with constructing expensive foundries when faced by uncertain demand. 
Likewise, foundries have been able to focus solely on manufacturing while somewhat immune to issues involving product demand. Variations of the fabless firm model have arisen, giving firms the flexibility to forego manufacturing altogether or specialize in their own assembly and/or testing.

The businesses in the earliest iteration of the industry often served all three discrete functions of production, but as the industry has matured, the required pace of technological advancement increased drastically. So too have the funds needed to develop those iterations and the equipment that enables them. Although vertical disintegration still occurs and there are various trends that could lend towards its favorability, most firms still favor scenarios in which they perform 1-2 distinct functions of production. While many tech giants are rushing to design and integrate their own chips and bring development in-house, the resources necessary to fabricate, assemble, and test those chips is prohibitive. In fact, only two firms consistently serve all distinct functions at once, those being Samsung and Intel. However, it should be noted that both firms also contract with third-party component suppliers and fabrication firms to bolster their own production.

Despite TSMC and Intel increasing their capacity dramatically with new fabs under construction, they have both announced increased production fees, creating downstream effects for both fabless firms and end consumers. ${ }^{34}$ Although these two most major manufacturers currently have something of a symbiotic relationship, their simultaneous construction of foundries puts them in a battle for talent and resources. Rising device complexity has also motivated the two most prominent equipment manufacturers, LAM Research and ASML, to continually increase the cost of their machinery. ${ }^{35}$ For these businesses, an imbalance between demand and supply creates a spurt of economic opportunity. Whilst other firms within the 
industry struggle with their rollout, LAM and ASML thrive in periods of growing capacity (see Fig. 6). Directly parallel to Moore's Law, the so-called Stokes' Law proposes that the cost of

\section{June Quarter Revenue Mix}

Record level of foundry and NAND revenue dollars

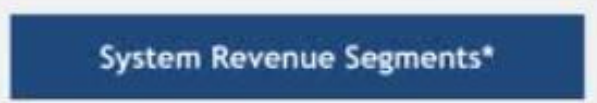

Logic/Other

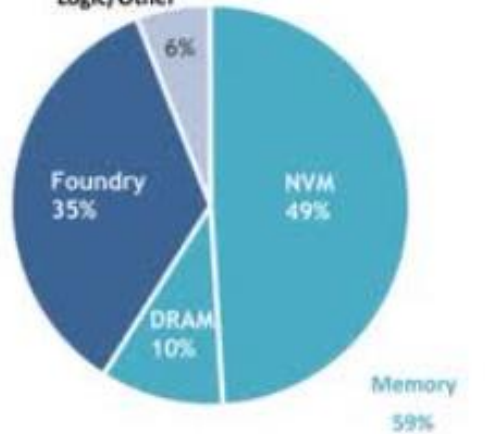

Revenue by Region

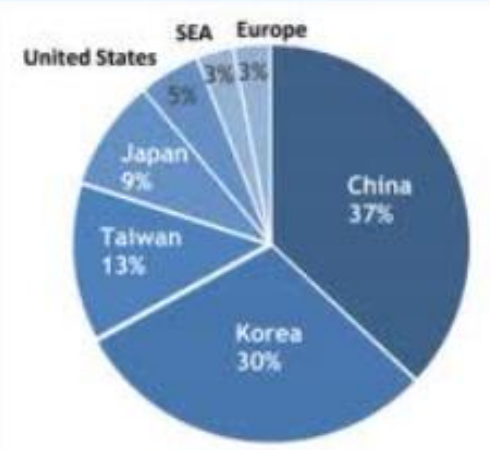

Figure 6: Q3 Financial Summary for LAM Research by Segment and Region (source: investor.lamresearch.com)

manufacturing within the industry roughly follows alongside transistor capacity. ASML, or Advanced Semiconductors Materials Lithography, is the industry's sole provider of the lithographic machines necessary to produce the most complex chips. Established in 1984, the Dutch manufacturing company’s first products cost as little as $\$ 300 \mathrm{~K}(\$ 798.6 \mathrm{k} \mathrm{AFI}) .{ }^{36} \mathrm{In} 2011$, the average cost of their machinery was roughly equivalent to $\$ 31.4 \mathrm{M} .{ }^{37}$ Due to the exponential increase in transistor density, ASML's next-generation machines are forecast to cost $\$ 150 \mathrm{M}^{38}$ The prohibitive cost of these machines continues to drive separation among the distinct firm 
types in the industry, prompting businesses to rely more on dedicated foundries to reduce fixed costs.

These production cost increases prompted AMD to spinoff their manufacturing arm into Global Foundries in 2008. ${ }^{39}$ And Intel, a firm which historically designed and manufactured their chips in house has required manufacturing assistance from TSMC since widening their product mix to include discrete graphics processing units, a surprising yet necessary business partnership. ${ }^{40}$ The technological advantages that TSMC enjoys has prompted many to consider the possibility of them adopting a retail arm of the business. However, like equipment manufacturers, TSMC benefits from having a sole function which enables them to amortize high fixed costs with contracting and production fees. Similarly, while subsidies will disproportionately benefit firms with dedicated foundries, increasing capital expenditures will likely prohibit fabless firms from expanding into manufacturing. The global distribution of these firms and their facilities, as well as the increased degree of specialization necessary to maintain financial viability has established the importance of supply chain efficiency and management. Additionally, it has drastically altered how firms interact and how they utilize modeling to gauge the performance of their supply chain.

Because the basic production process for integrated circuits (ICs) is relatively similar across technologies, certain supply chain trends prevail. The majority of these introduce an element of uncertainty, mostly concerning the supply and distribution of raw materials, the use of which varies widely by firm. While the underlying science necessary to improve yields and efficiency is complex and expensive, it is one of the sole ways fabless manufacturers can benefit from what is contentiously fought-over supply of materials. Yield uncertainty is also exaggerated by the characteristically short product cycles within the industry. As new technologies and 
products are developed, the introduction of new methods and materials necessarily gives rise to inefficiency. Again, this is something of a continuous issue for fabless firms since they must balance the development of new products with the high production cost of the utilized materials.

As previously mentioned, the semiconductor industry is also severely affected by irregular business cycles which fluctuate according to macroeconomic wellbeing. For example, global shipments between 1958 and 2007 varied from between -40\% and 70\% in five-year cycle periods. ${ }^{41}$ Additionally, manufacturers must continually evaluate whether make-to-stock (MTS) or make-to-order (MTO) structures benefit them more. Volume manufacturing is generally favored by MTO production whilst the production of specialized products should utilize an MTS mode. ${ }^{42}$ One of the most fundamental issues in the supply chain is the determination of which products become more reasonable under which mode of production, each faces their own advantages and disadvantages.

If the firm operates in MTS mode, they are often able to maintain high levels of inventory to amortize their high fixed costs as much as possible. However, the MTS mode of production comes without contractual agreements for production amounts, meaning there is no guarantee foundries will be able to distribute the extra inventory they produce. On the other hand, the MTO mode of production does come with contractual agreements, lending stability and visibility into future demand. However, the ramp on MTO environments is more severe, resulting in undesirably long cycle times. Some firms cope with this by utilizing modular designs which allow for many different finished products to be constructed from a bank of semi-finished wafers. ${ }^{43}$ In addition to this supply chain strategy, the decision of how to resource certain components must also be continuously evaluated. Both decisions have historically been made using a hierarchical decision support framework based on customer lead time and what materials 
are required to compose specific components. ${ }^{44}$ Although these decisions are ubiquitous throughout any sector, the process within the semiconductor industry is once again made more complex by rapid and unpredictable business cycles and short lead times. Therefore, analytical frameworks addressing other characteristics of the supply chain must also be utilized.

Discrete-event simulation (DES) is a well-established analytical tool which enables production facilities to compile data and produce statistically valid results which indicate the efficiency (or lack thereof) based on a firm's interactions with the supply chain. Because the computational burden of the model is high, researchers have proposed that focusing only on certain process steps will solve computative bottleneck concerns whilst still yielding accurate results. ${ }^{45}$ Capacity, yield, and delay are split into separate modules used to determine the number of lots a firm can expect from their manufacturing process, the timing of those units' distribution, and how efficient the process will be. ${ }^{46}$ Historical data is also utilized to create probability distributions estimating the cycle time for upcoming production ramps. However, the DES model used assumes that these distributions for cycle times operate independent of resource utilization and supply, an assumption which the most recent shortage has proved thoroughly unreasonable. ${ }^{47}$

While a helpful resource, it is difficult to examine or state just how well these modeling techniques work. The amount of data and time needed to produce such computations is largely prohibitive, especially with shifting variables and short production cycles. These models and their development constitute an entirely separate realm of research and analysis a firm must undergo if they want both a successful and predictable production cycle. Like with designing both a competitive and efficient product platform, undergoing this process may result in a competitive advantage, or it may prove to be a waste of time and money. Still, because of the vertical integration and specialization of firms, many entities within the industry remain distant 
from other steps in the supply chain. The degree of control they have in determining its efficiency and value is limited to utilizing these datasets and hoping they return statistically legitimate results. The sheer size of the industry accompanied with its pace means maximizing the return of the supply chain is often difficult for back-end firms. In other words, what can be done to draw efficiency from the supply chain, no matter the function of the firm, is already being done. While incremental improvements in efficiency and resource utilization can be made generationally, Moore's Law continuously marches on and requires iteration on old strategies. However, improvements can always be made to the byproducts of the supply chain.

One of the most ubiquitous topics within any industry is the sustainability of their supply chain and what negative impacts it may have. Semiconductor manufacturing particularly is highly resource intensive. A single wafer fab facility may consume as much as $\$ 10 \mathrm{M}-\$ 20 \mathrm{M}$ in energy consumption, a fee only bound to rise due to larger fab sizes. ${ }^{48}$ The emittance of CO2 and other greenhouse gases and the use of perfluorocarbons (PFCs) are also both notably high.

Despite this being a glaring issue with semiconductor production, it demands relatively little attention from researchers and industry experts. Papers suggesting infrastructural solutions to these issues remain few and far between. However, Santana-Viera et al. have proposed a new power generation system which takes better advantage of renewable resources and creates a more efficient distribution to optimize square footage. Specifically, the design would utilize photovoltaic cells and onsite wind generation to further amortize the high fixed costs of semiconductor manufacturing facilities via energy savings and offsets. ${ }^{49}$ However, the financial reasoning for installing PV cells and wind turbines can be difficult to establish. Much of the proforma analysis necessary to justify such a decision would be based on highly fluctuating variables such as energy costs, the occurrence of natural disasters and their disruption of the 
energy infrastructure, and other unpredictable events. ${ }^{50}$ In their 2016 paper, Hwang et al. compiled a framework to analyze the relationship between manufacturing firm, supplier, and environment. Causal relationships among these factors are evaluated using a quantitative methodology weighted based on the opinions of industry experts. An analysis of these causal relationships suggests there may be a quantifiable competitive advantage associated with reducing impacts on the environment, but that the infrastructural improvements necessary to make the supply chain green are often more expensive than unquantifiable or uncertain social advantages.

Alternatively, Chiang et al. propose an operational solution which would introduce less infrastructural improvements but rely on incorporating environmental considerations into the semiconductor manufacturing process. Carbon taxes and subsidies seek to offset greenhouse emittance, though the amount necessary to accomplish this on any large scale would drain firms of their financial resources. ${ }^{51}$ The most likely proposal that would achieve this goal is a linear model that charges a firm based on their capacity or contractual agreements with a fixed variable assigned according to that firms estimated greenhouse emissions. These models would also be able to weight the allowance of particularly harmful byproducts or chemicals in the production process. In a field dominated by obsessively constant and rapid technical progression, the impacts on an already heavily polluted world and what solutions may remediate them may seem a distraction. However, the resources contributed towards technical development could easily be reduced to a level where at least some of the industry's emissions are offset. While this is generalizable across many industries, it is an especially important issue for the semiconductor industry to resolve given the ever-increasing application of semiconductors in diverse sets of products. (see Fig. 7). 


\section{Chip Producers Overtaking Automakers as Polluters} The environmental cost of semiconductors is rising

Intel $/ \mathrm{TSMC} / \mathrm{GM}$

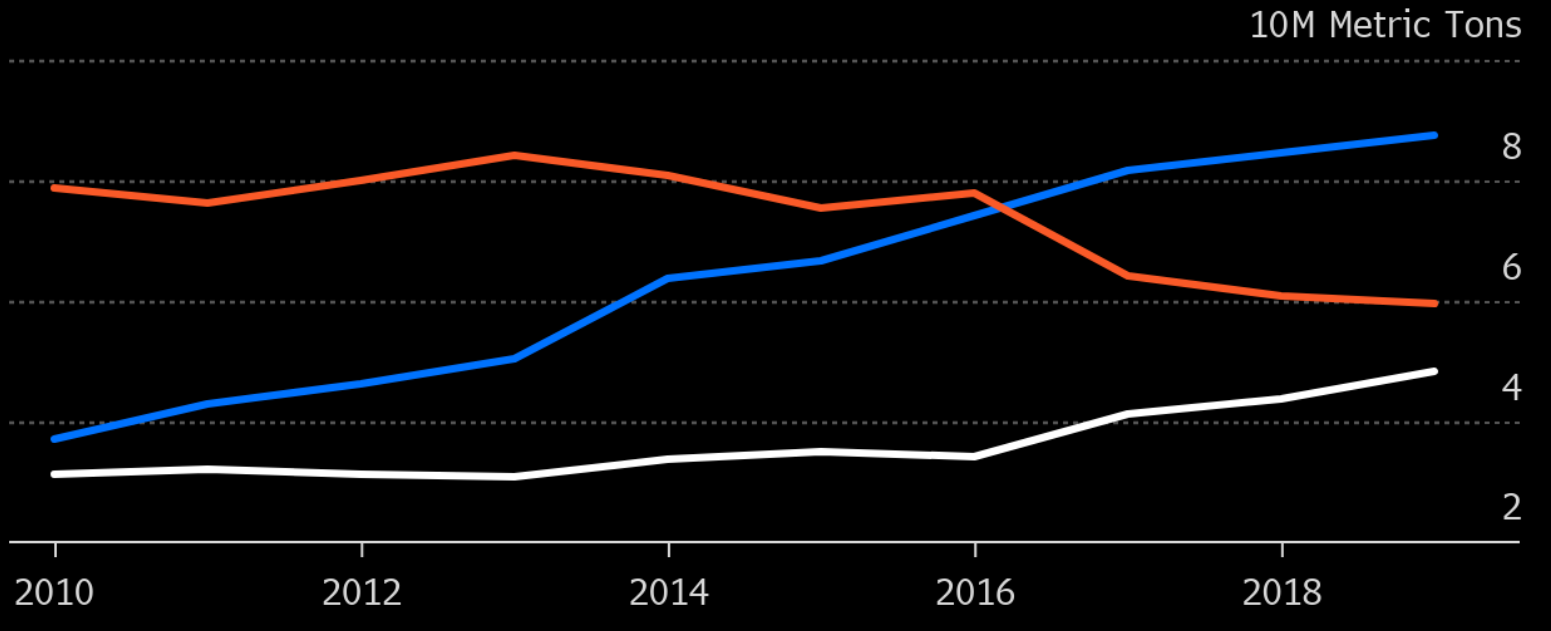

Source: Company disclosures

Note: Metric tons of green house gas emissions

Bloomberg

Figure 7: Greenhouse Gas Emissions of Semiconductor and Automotive Companies (source:

\section{Bloomberg.com $)^{52}$}

\section{Firm Financing and Repositioning}

As mentioned previously, many firms' response to the semiconductor shortage is to immediately expand or prioritize capacity. The construction of fabs is immensely expensive and significantly impacts the business' resources. However, more subtle cash outflows or cases of financial repositioning must also be considered. Different firm types will have diverse abilities and strategies in manipulating their resources. Therefore, a more in-depth analysis of their strategies becomes necessary in understanding how these changes interact. 
The semiconductor industry depends heavily on iterative innovation on previous technological advancements, the demands for which become progressively more intense as competition rises. These developments are often discovered by utilizing inter-organizational relationships and strategies. For example, AMD's products take advantage of their manufacturer, TSMC, and their technological expertise. The firm's CPUs would not be nearly as performant were they not able to take advantage of TSMC's 5- and 3-nanometer technology. However, the fees resulting from these inter-firm interactions are ill-defined and the conditions unclear. Due to this high level of uncertainty, bargaining and financial power is centralized in the firm that supplies their technological designs.

Firms create these synergies not only to share the burden of innovation, but due to fluctuations within the industry. Collaboration allows them to share risks and expenses by pooling their financial and intellectual resources. ${ }^{53}$ These businesses must be integrated not only via their $R \& D$ and manufacturing process, but their entire network must be collaborative. Because system technologies are only viable if all components are serviceable and on-time, the failure or dysfunction of a single component can materially hinder a product launch. In these partnerships, the semiconductor manufacturers provide financial support to component suppliers to reduce development risk. Although many firms are powerful enough to demand a fortified supply chain without synergies, smaller ones require organizational cooperation to guarantee a functioning supply of components. ${ }^{54}$

While this characteristic of the industry makes it more difficult to analyze the financial motivations of firms, it will hereafter be assumed that all firms have some sort of synergies in place, even those that appear competitively opposed. These partnerships materialize via both marketing and component agreements. For example, AMD and Nvidia regularly partner to 
integrate their technologies despite their GPUs being competitively opposed. To take advantage of AMD's strong data center chips, Nvidia's DGX A100, used for heavy computation and research workloads, utilizes AMD's dies for the product's machine-learning nodes. While these partnerships appear strange given the competition within the industry, every firm must maintain a diverse and distinct product line. So, although AMD and Nvidia compete via their GPU lines, their other product mixes, such as their data center platforms, often depend on collaboration between the firms. In this case, the firms' technological motivations for collaboration are clear, but the implications for market share are also relevant. Compared to Intel, AMD and Nvidia both enjoy relatively small market share in the domestic electronics market (see Fig. 8). By using collaborative technologies, they help each other by promoting parity within the market,

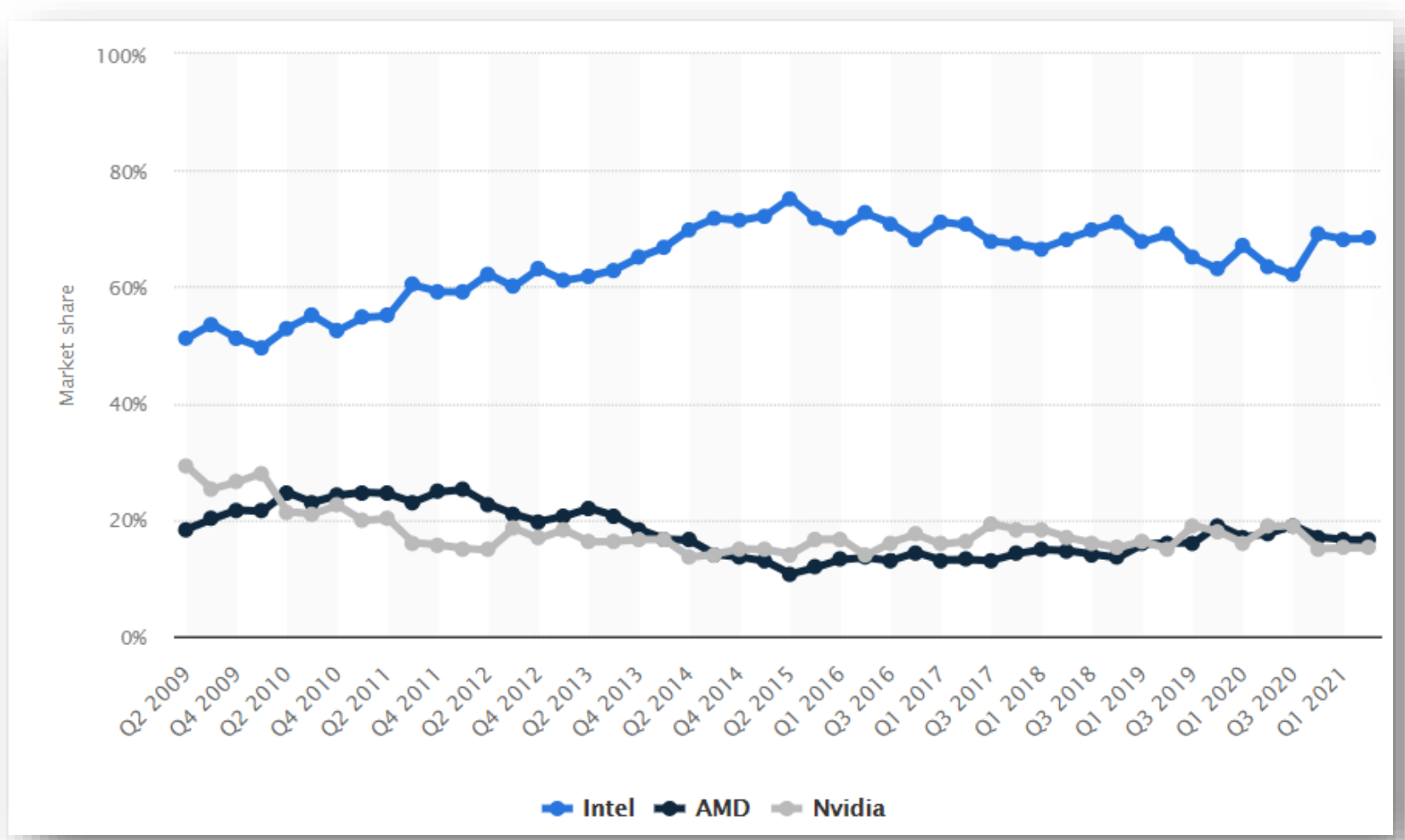

Figure 8: PC GPU (iGPU \& dGPU) Global Shipments (2009-2021 Q2; source: statista.com) ${ }^{55}$ 
slowly gaining market share to compete with Intel's strong graphics positioning.

In turn, Intel has responded with their own intra-firm collaboration to bolster their graphics dominance. Previously, only Nvidia and AMD produced and designed discrete GPUs, with Intel focusing on integrated graphics within their mobile and desktop CPUs. However, as more intense graphics requirements become necessary for workstation and content creation workloads, discrete GPUs rise in popularity, prompting Intel to launch their own line of discrete graphics cards. To accomplish a performant platform launch, Intel openly partnered with TSMC to cope with both capacity and cost restraints. Additionally, since TSMC has previously assisted other firms in GPU manufacturing, their supply of components is likely more robust than Intel's. ${ }^{56}$ Additionally, these capacity demands from Intel limit the production available to AMD and Nvidia, who both contract with TSMC to produce their GPUs. Partnerships within the industry have innumerable motivations and impacts on the market and the firms within it. The inconsistent and perpetually shifting nature of these businesses both necessitate these collaborations and preclude their ongoing existence as financial and technological requirements and resources change.

Regardless of the source of funding, whether it is produced externally or provided within the firm, there are generally two major destinations for dedicated resources. As previously mentioned, capital expenditures and research and development are the major expenses within the industry. An efficient and productive mix of these major cash outflows is necessary to maximize a firm's future potential, and since the industry is obsessively focused on iterative development, the ratios must constantly be adjusted. Much like product development and production, financial budgets and the firms' spending must be planned well in advance to cope with changes within the industry. However, the strained supply chain and its effect on the industry have forced 
manufacturers' hands. Both TSMC and Intel have rapidly shifted to capacity prioritization, whilst amid historically high competition. These factors have greatly influenced the decisions of firms, meaning that both CAPEX and research \& development have been levered as high as is financially advisable. Although the businesses are still exceedingly viable and healthy, their margins are lower against historical comparisons as their expenditures have ramped up. The graphs below show historical data financial data for Intel, AMD, Nvidia, and TSMC, including net margin, R\&D expenditures, and capital investments (see Figures 9-11). ${ }^{57}$

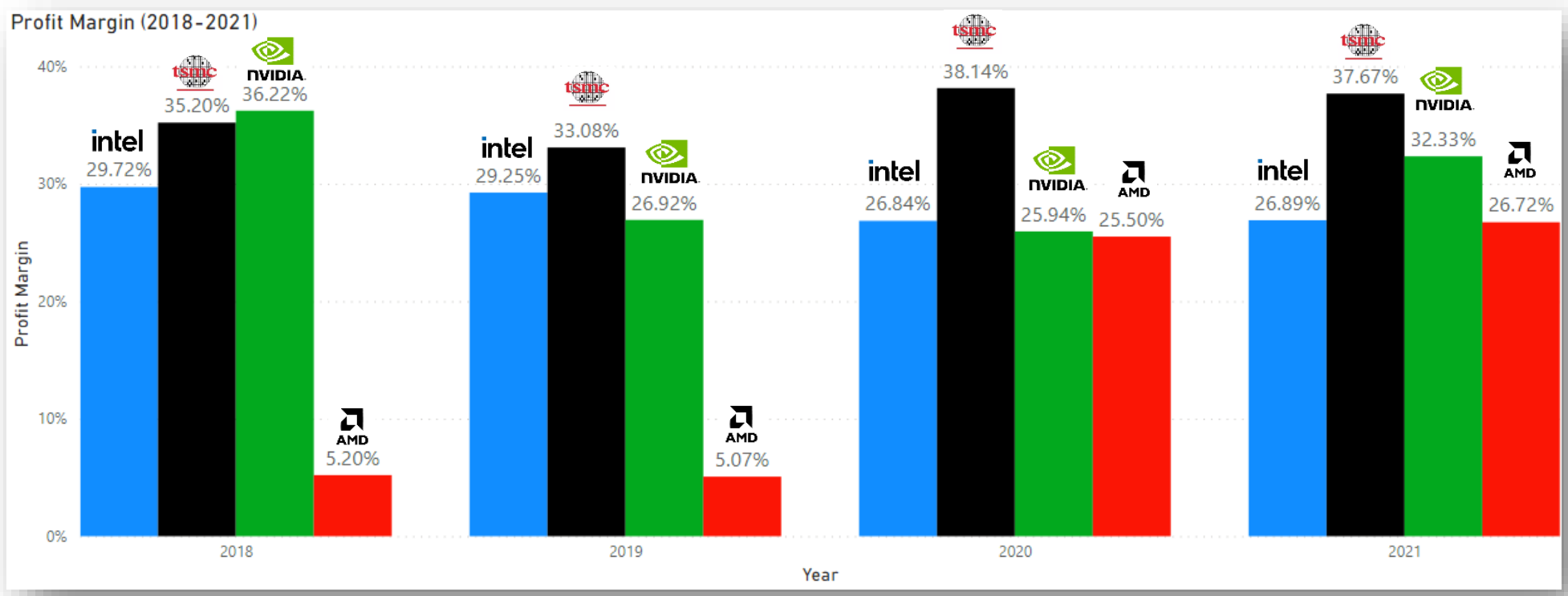

Figure 9: Profit Margin for Various Firms (2018-2021, source: various 10Ks)

Historically, the margins for these businesses have been remarkably consistent despite the need for rapid iterative development. Although high competition has led to lower sales prices, the number of unit sales and product launches per year make up for this. While the analysis of inter-firm success, or lack thereof, is not in scope for this paper, AMD's meteoric success in recent years reflects the competitive nature of the industry. The launch of their Zen line in 2017 challenged Intel for the first time in decades. Meanwhile, as Intel develops and launches their 
discrete graphics line, they will also challenge AMD and Nvidia to increase the cadence of their discrete product launches and decrease the sales price of their units.
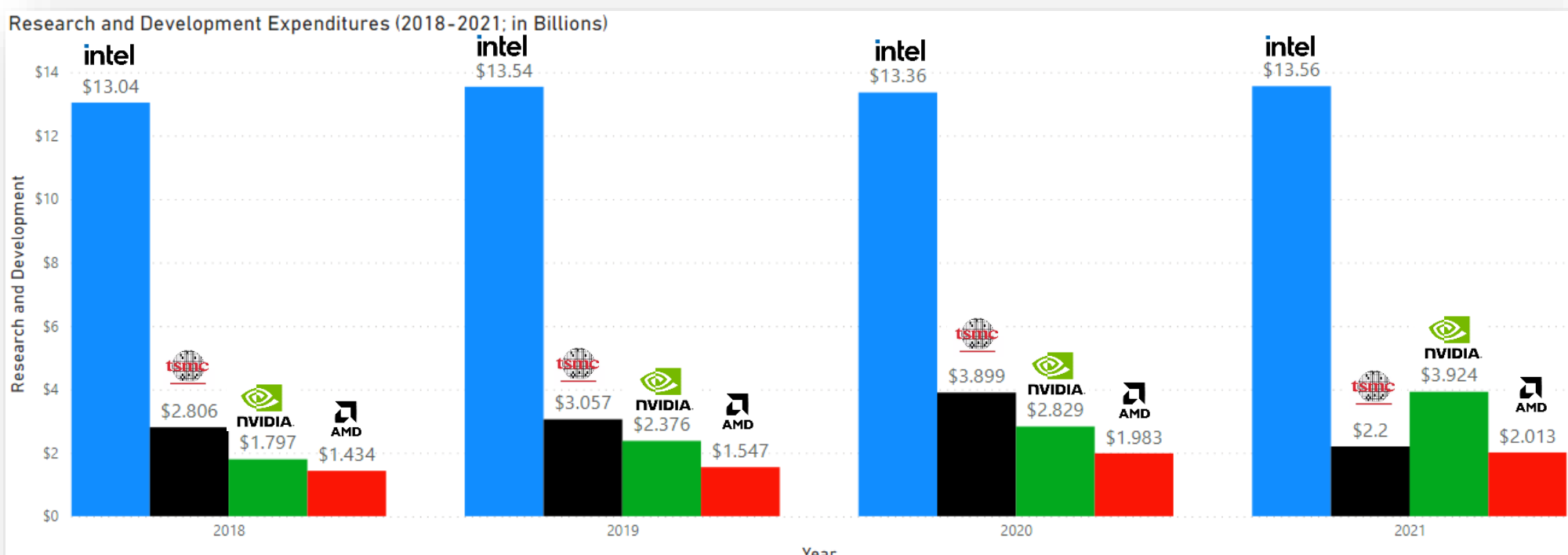

Figure 10: Research and Development for Various Firms (2018-2021, source: various 10Ks)

Implied by this high degree of competition is the necessity for continuous improvement and innovation. While this measure differs greatly by firm type and scale, competitors must respond to the investment of outside firms by levering up their research. Most of these expenses have to do with designing new architecture, maximizing the efficiency of current designs, and subsequently engineering chips that extend Moore's Law. ${ }^{60}$ Of course, the exact focus of every firm's research will remain confidential until products release, but generating breakthroughs in chip architecture while emphasizing new areas of focus such as AI, VR/AR, high-performance computing, and immersive tech is the primary and ever-lasting objective of every semiconductor firm. 

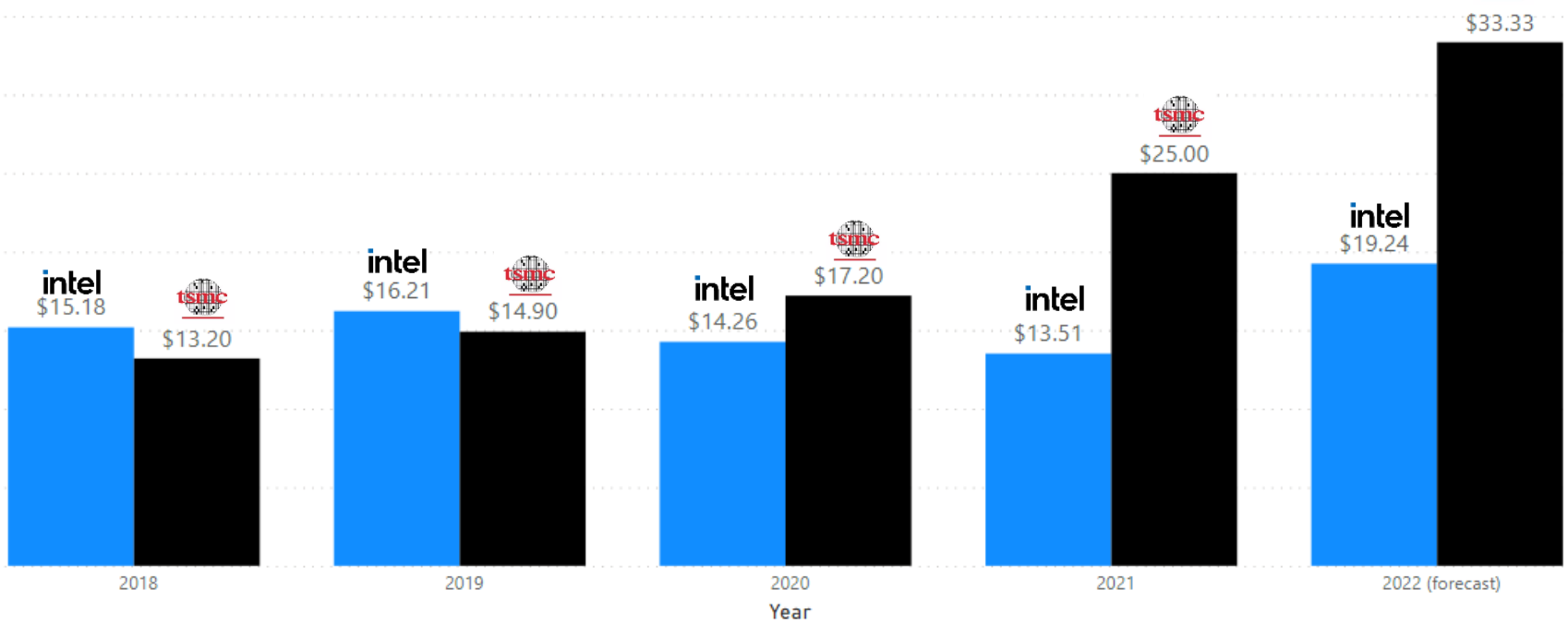

Figure 11: Capital Expenditures for Various Firms (2018-2021, source: various 10Ks)

Both Intel and TSMC plan to allocate enormous amounts of resources to building fabs and infrastructure. Intel's capital expenditures are expected to average \$19.273B per year over the next five years. ${ }^{58}$ Meanwhile, TSMC has already pledged to spend $\$ 100 \mathrm{~B}$ over the next three years for R\&D and capital investment. ${ }^{59}$ Production capacity is an unwavering theme of the industry, and although the shortage has necessitated urgent response, experts wonder if the sudden and drastic investment in new fabs will not harm TSMC's and Intel's ability to innovate.

The semiconductor industry is highly reactive to logistic instability. Moreover, firms are reactionary to the decisions of other firms, creating a cycle of short-lived competitive and technical advantages. However, neither production capacity nor research \& development will help firms cope with component shortages and other supply chain difficulties. Shortages and frugality among consumers drastically affected product rollouts in 2020 , leading to slightly lower margins for retail firms. As time goes on, margins will continue to be impacted by high 
expenditures. However, many forecast demand to continuously increase over the short-term, at least for the 10- and 14-nanometer chips that many downstream consumers integrate into their appliances, vehicles, etc.

Meanwhile, component suppliers and the supply chain must seek process improvements in order for businesses to take advantage of the future capacity increases. Component supply and the consistency of the semiconductor supply chain may occasionally falter, but the goal of the industry will always be to prolong and attend to Moore's Law. Although the continuation of this industry tenet leads to more affordable and performant products at a constant rate, the resources needed to accomplish this increase exponentially and define the future of the industry. Because new and innovative methods for extending Moore's Law are so resource-consumptive, the primary driver for its continuation is the need for competitive advantages. Were there a monopoly, there would theoretically be a point where incremental improvements become too expensive to develop and the industry would stagnate. However, because the industry has been competitive since its very beginning, the need for iterative development has always persisted.

For consumers and for society, Moore's Law is essential. No human invention has ever exhibited the rate of improvement so precisely summarized by Gordon Moore. Upon its creation, it defined the electronics industry and made it one of the most impactful and financially prosperous markets in the world. The invention of consumer electronics, minicomputers, servers, personal computers, and the internet have relied entirely upon Moore's Law. Were firms to agree upon stagnation, it would crash both the electronics industry- and thereby, the economy-as well as the state of innovation. Therefore, since the creation of the industry, each inhabitant has been engaged in a constant and very expensive arms race. No matter what else happens, 
accomplishing higher performance with a regular (and quickening) cadence will keep the industry and its firms afloat.

Their undying dedication to innovation renders firms a degree of inflexibility. No matter what condition they are in, firms must dedicate an appropriate amount of funds to finance future plans. Unfortunately, this severely reduces their ability to mitigate potential shortages.

Development that simultaneously increases transistor density while also exploring the usage of more consistently available components may be an answer, but the usage of certain components is directly tied to a firm's product platform, making this a costly and risky transition. Instead, the largest and most financially viable firms must commit to investing in or even subsidizing component suppliers. As demand for both complex and simple semiconductors continue to increase, a steady stream of components will dictate the future of the industry. Like with all shortages currently affecting the macroeconomy, one of the only ways to reliably remediate future issues is to bolster the supply chain and support the originators of essential materials and services. Ensuring components are sourced sustainably and that shipping and other methods of distribution are reliable and well-funded is essential for the ongoing health of the industry, and this will require investment and dedication from every major firm. This holds true for all industries currently suffering, but given the vertical integration within the semiconductor industry, an unreliable supply chain can ruin smaller firms in a matter of months.

\section{Scenarios and Implications}

Hitherto, the various solutions and remedies the semiconductor industry relies on to cushion itself from fluctuation have been described, but the downstream effects and implications have been left relatively ambiguous. In large part, this is due to the fluctuation and irregular structure 
that characterizes the semiconductor industry. A research commitment by one firm may either reap an enormous advantage, or fall flat, depending entirely on competition, timing, supply \& demand, and other external factors. While this is true for any business' development period, the chaos and the uncertainty of this industry makes theoretical scenarios nearly impossible to identify and analyze on a single-firm level. Still, scenario analysis is a constant within the industry and is immensely important to the future wellbeing of the market. In the absence of datasets, individual firm analysis is impossible. However, by gauging the current state of the industry and applying different hypothetical lenses to it, analysts can better understand what remediations have already been enacted and which firms may be considering. The following section will describe, apply, and measure the impact of various standalone or parallel shortage solutions.

Beginning broadly, the effect of incoming subsidies and legislature could be industrydefining. Formulated in equal parts to respond to the trade war with China and the pandemic, these subsidies will lend firms the financial bulwark needed to weather future issues in two ways. First, they will directly benefit chip manufacturers by providing them funds to construct facilities and infrastructure to increase production capacity. Fabless design firms will directly benefit from increased capacity in the short-term, but demand may increase to the point where these improvements are only marginal. Additionally, equipment manufacturers will enjoy a period of heightened demand, - albeit a period already in full swing- giving them the funds and flexibility to explore new breakthroughs and drive the industry further. Second, the current legislature bill dedicates resources to establish and fund a national research facility. No matter where it is directed, research \& development motivates technological advancement within the industry. However, this piece of legislation is more reactive than proactive. Simply put, Chinese subsidies 
forced the government's hand; domestic firms cannot afford to fall behind Chinese firms any longer. The rate at which resources are consumed to produce iterative improvements makes the dedicated \$16.2B per year for five years seem relatively paltry. Contextually speaking, that's still \$3B less than Intel is projected to spend in $2022 .{ }^{60}$ Assuming this research is done with a similar efficiency to the industry standard, it will certainly assist firms in extending Moore's Law and improving significantly.

Despite the potential boon government-funded research offers, numerous issues persist. First, domestic firms are already working at a disadvantage and research takes years to affect firms' decision-making. Second, while the amount dedicated may be enough to achieve global parity within the industry given unshifting variables, Chinese firms have enjoyed research subsidies for markedly longer than domestic firms. Realistically, domestic firms can expect to be in the same position as they currently are five years down the line. Most importantly, these research subsidies may become a crutch for the domestic industry. No doubt the shortage has catalyzed research \& development prioritization for every firm. However, if China subsidizes the research of TSMC and others, the state of the domestic industry depends on the American government doing the same.

Regardless of the future result of government research subsidies, ensuring that the industry's supply chain is well-equipped and efficient is necessary. By collecting lead time, supplier, and inventory data from major firms, the Biden Administration has committed to ensuring the ongoing viability of the supply chain. ${ }^{61}$ Identifying the various bottlenecks in the global supply chain will help the industry to cope with and predict future challenges. The shortage has significantly affected several sectors, to the point where automobile and semiconductor executives lobbied alongside one another for the subsidies and oversight to pass. 
Given its scope, legislation to fix supply chain issues will lend the industry ongoing security and prevent future issues from destabilizing the economy. However, government involvement is not enough to stimy supply chain instability. Firms must also commit to supporting their suppliers and distributors enough to prevent potential gaps. While some may not view this as the responsibility of individual firms, the onus to create a more reliable industry is on them. Regular analysis and oversight of their own logistical bandwidth will enable firms to develop and produce chipsets without interruption of supplies, thereby bolstering the viability of the industry. Simply put, industry standards must change for the current development and production cadences to remain attainable.

In the first week of October, America's second largest foundry, GlobalFoundries, announced that they had sold out of production capacity through $2023 .{ }^{62}$ Many experts expect that the industry will be chasing supply, not demand, for the determinable future ${ }^{63}$ Increasing production capacity is a natural response to the shortage. It benefits manufacturers by allowing them to maximize profits whilst giving fabless design firms the bandwidth to do the same. Given the trajectory of the industry, capacity increases are necessary. However, were demand to suddenly shift lower in the next 5-10 years, a glut could spell disaster for many small firms. Firms must recognize the possibility of this occurring and prioritize their investment activities very carefully. Because a supply surplus would force firms to sell units at survival cost, they must maintain a financial cushion that will keep them afloat during such a period. Similarly, firms' attention must always be geared towards future progression. Capacity increases and financial bulwarks will do them little good if their chips are generations behind. Therefore, the potential impact of increased production capacity is only realized when a firm's finances are well-balanced and appropriately allocated. 
Achieving iterative improvements has set the pace of the semiconductor industry since its founding. Regardless of firm structure and capability, research and development will always be the most essential component of building a viable semiconductor firm. Rather than dedicating an exponentially greater amount of resources into technical advancement- something already required by Moore's Law- it is more apropos to ensure that a firm's R\&D investments remain efficient and appropriately speculative. Given its confidential nature, research scenarios are difficult to generalize and analyze. However, as the funds required to iterate increase, a misstep becomes continuously more costly. Analytical frameworks and appropriate product platform development will help firms avoid major pitfalls in their research phase, ensuring their future security. Simultaneously, the industry would be nowhere if firms did not take risks. Speculative breakthroughs in architecture, component usage, and instruction sets can give firms a material competitive advantage. Depending on the technical capability of any individual firm, the appropriate mix of risk and certainty in the development phase will differ greatly. Regardless, striking that balance adequately is perhaps the most important thing a firm can do to guarantee its future. The semiconductor industry is at a crossroads, and the actions and decisions of a few major firms will dictate the future of not only the industry, but the world and macroeconomy.

\section{Conclusion}

Although the semiconductor industry has experienced innumerable downturns due to supply gluts or recessions, it has been forever changed by this most recent shortage. While capacity and component supply restraints have always existed, the ongoing shortage shows no signs of abating until at least 2023. Moreover, fiscal \& monetary policy, capacity increases, and both internal and non-firm innovation will do nothing to shorten it. By the time any of those changes are enacted, the shortage will have been over with. Instead, the shortage should signal to the industry a need 
for permanent change. Whilst extending Moore's Law and expanding capacity, there must also be investments to build a more hardy, sustainable, and efficient supply chain. Product platforms, previously developed to handle the production of multiple products, can be more flexibly designed to take advantage of a range of components. While the largest firms already have ample financial cushions, these changes will protect them and the marketplace against future issues.

Due to the vertical integration within this industry, efficiency maximization whilst still maintaining a beneficial intra-firm structure is difficult, though mandatory. Moreover, the diverging capabilities of firms within the industry create obstacles for material and ubiquitous change. Catalysts for issues may vary from being logistical, financial, or technical in nature, making them difficult for any one firm to adequately address. However, the future of the economy largely relies on the reliable and steady progression of the semiconductor industry. The application of its products into cars, appliances, and other consumer goods has led to rapid growth for many sectors. And now, as with Moore's Law, breaking that chain would result in a multi-generational economic trough characterized by halting innovation. In many ways, the creation of the semiconductor industry led humankind to many different, hugely implicative discoveries. Now, as the industry reaches a hitherto incomprehensible scale, its beneficial impact must be extended and its negative consequences reigned in. 


\section{Bibliography}

Allan, A. (2001, April). Business cycle market/demand forecasts vs. TSCR cycle model.

In International SEMATECH. Presentation at the global economic workshop, Monterey, California, USA.

AMD. (2021, January). Form 10-K. Retrieved from NetAdvantage database.

Barlevy, G. (2004). On the Timing of Innovation in Stochastic Schumpeterian Growth Models. SSRN Electronic Journal. Published. https://doi.org/10.2139/ssrn.583803

Belvardi, G. (2012). Monte Carlo Simulation Based Performance Analysis of Supply Chains. International Journal of Managing Value and Supply Chains, 3(2), 1-15. https://doi.org/10.5121/ijmvsc.2012.3201

Bottani, E., Mantovani, M., Montanari, R., \& Vignali, G. (2017). Inventory management in the presence of inventory inaccuracies: an economic analysis by discrete-event simulation. International Journal of Supply Chain and Inventory Management, 2(1), 39. https://doi.org/10.1504/ijscim.2017.086374

Brown, A. O., Lee, H. L., \& Petrakian, R. (2000). Xilinx Improves Its Semiconductor Supply Chain Using Product and Process Postponement. Interfaces, 30(4), 65-80. https://doi.org/10.1287/inte.30.4.65.11650

Cherney, M. A. (2021, March 27). Intel Presents a \$20 Billion Bill for a Turnaround. Investors Don’t Like It. Barron's. https:/www.barrons.com/articles/intel-presents-a-20-billion-billfor-a-turnaround-investors-dont-like-it-51616805452

Chin, C. L., Lee, P., Chi, H. Y., \& Anandarajan, A. (2006). Patent Citation, R\&D Spillover, and Tobin's Q: Evidence from Taiwan Semiconductor Industry. Review of Quantitative Finance and Accounting, 26(1), 67-84. https://doi.org/10.1007/s11156-006-7034-1

Clark, D. (2021, November 8). Chip Shortage Creates New Power Players. The New York Times. https://www.nytimes.com/2021/11/08/technology/computer-chip-shortage.html

Coombs, J. E., \& Bierly, P. E. (2006). Measuring technological capability and performance. $R$ and D Management, 36(4), 421-438. https://doi.org/10.1111/j.1467-9310.2006.00444.x

Crawford, A., King, I., \& Wu, D. (2021, August 4). The Chip Industry Has a Problem With Its Giant Carbon Footprint. Bloomberg. https://www.bloomberg.com/news/articles/202104-08/the-chip-industry-has-a-problem-with-its-giant-carbon-footprint 
Cutress, I. (2021, October 21). Intel Reaffirms: Our Discrete GPUs Will Be On Shelves in Q1 2022. AnandTech. https://www.anandtech.com/show/17026/intel-reaffirms-our-discretegpus-will-be-on-shelves-in-q1-2022

Dyckhoff, H., Dirksen, A., \& Mbock, E. (2012). Measuring the Balanced Efficiency of Decision Making Units. SSRN Electronic Journal. Published. https://doi.org/10.2139/ssrn.1990233

Guan, J., \& Chen, K. (2010). Measuring the innovation production process: A cross-region empirical study of China's high-tech innovations. Technovation, 30(5-6), 348-358. https://doi.org/10.1016/j.technovation.2010.02.001

Haneda, S., \& Odagiri, H. (1998). Appropriation Of Returns From Technological Assets And The Values Of Patents And R\&D In Japanese High-Tech Firms $\dagger$. Economics of Innovation and New Technology, 7(4), 303-321. https://doi.org/10.1080/10438599800000038

Hung, Y. F., \& Leachman, R. (1999). Reduced simulation models of wafer fabrication facilities. International Journal of Production Research, 37(12), 2685-2701. https://doi.org/10.1080/002075499190473

Hwang, B. N., Huang, C. Y., \& Wu, C. H. (2016). A TOE Approach to Establish a Green Supply Chain Adoption Decision Model in the Semiconductor Industry. Sustainability, 8(2), 168. https://doi.org/10.3390/su8020168

Intel. (2021, January). Form 10-K. Retrieved from NetAdvantage database.

King, I. (2021a, October 10). China stockpiles chips and chip making machines to resist U.S. Bloomberg. https://www.bloomberg.com/news/articles/2021-02-02/china-stockpileschips-and-chip-making-machines-to-resist-u-s

King, I. (2021b, October 10). Chip Delivery Time Surpasses 20 Weeks in No Sign Shortage Easing. Bloomberg. https://www.bloomberg.com/news/articles/2021-08-10/chipdelivery-time-surpasses-20-weeks-in-no-sign-shortage-easing

Knight, W. (2021, August 30). The $\$ 150$ Million Machine Keeping Moore's Law Alive. Wired. https://www.wired.com/story/asml-extreme-ultraviolet-lithography-chips-moores-law/ Leckie, R. (2001). The semiconductor cycle-Here we go again. Infrastructure. Special report sponsored by Scottish Enterprise. Infrastructure, Irving, Texas. 
Leswing, K. (2021, November 1). GlobalFoundries CEO: We're sold out of semiconductor chip capacity through 2023. CNBC. https://www.cnbc.com/2021/10/30/globalfoundries-ceowere-sold-out-of-semiconductor-chip-capacity-through-2023.html

Li, Y., Huang, M., \& Chen, D. (2011). Semiconductor industry value chain: characters' technology evolution. Industrial Management \& Data Systems, 111(3), 370-390. https://doi.org/10.1108/02635571111118260

Liu, W. H., \& Chyi, Y. L. (2006). A Markov regime-switching model for the semiconductor industry cycles. Economic Modelling, 23(4), 569-578. https://doi.org/10.1016/j.econmod.2006.02.007

Liu, W.-H. (2005). Determinants of the semiconductor industry cycles. Journal of Policy Modeling, 27(7), 853-866. https://doi.org/10.1016/j.jpolmod.2005.05.009

Lu, W. M., \& Hung, S. W. (2008). Assessing the performance of a vertically disintegrated chain by the DEA approach-a case study of Taiwanese semiconductor firms. International Journal of Production Research, 48(4), 1155-1170. https://doi.org/10.1080/00207540802484929

MALIAR, L., \& MALIAR, S. (2004). ENDOGENOUS GROWTH AND ENDOGENOUS BUSINESS CYCLES. Macroeconomic Dynamics, 8(5), 559-581. https://doi.org/10.1017/s1365100504040064

Manufacturing systems integration. (1990). Computer Integrated Manufacturing Systems, 3(2), 121. https://doi.org/10.1016/0951-5240(90)90115-u

McClean, B. (2001). IC industry at the crossroads. Semiconductor International, 24(1), 73-75.

Nellis, S. (2021, September 25). Intel breaks ground on $\$ 20$ bln Arizona plants as U.S. chip factory race heats up. Reuters. https://www.reuters.com/technology/intel-breaks-ground20-bln-arizona-plants-us-chip-factory-race-heats-up-2021-09-24/

Nvidia. (2021, October). Form 10-K. Retrieved from NetAdvantage database.

Oregonian/OregonLive, T. R. M.|. (2021, October 27). Intel promises another decade of Moore's Law as it strives to reconnect with 'geeks.' Oregonlive. https://www.oregonlive.com/silicon-forest/2021/10/intel-promises-another-decade-ofmoores-law-as-it-strives-to-reconnect-with-geeks.html 
Park, K. (2021, November 7). South Korean chipmakers will submit semiconductor data to the U.S. by Nov. 8 deadline. TechCrunch. https://techcrunch.com/2021/11/07/south-koreanchipmakers-will-submit-semiconductor-data-to-the-u-s-by-nov-8-deadline/

PricewaterhouseCoopers. (2020, August 10). Opportunities for the global semiconductor market: Growing market share by embracing AI. PwC. https://www.pwc.com/gx/en/industries/tmt/publications/global-tmt-semiconductor-report2019.html

Ravi, S. (2021, March 1). Semiconductor Shortage Highlights Need to Strengthen U.S. Chip Manufacturing, Research. Semiconductor Industry Association. https://www.semiconductors.org/semiconductor-shortage-highlights-need-to-strengthenu-s-chip-manufacturing-research/

Rees, K., Schussler, K., Wittenstein, J., \& Remondini, C. (2021, March 30). Here's How the World's Chip Shortage Is Playing Out for Stocks. BloombergQuint. https://www.bloombergquint.com/technology/here-s-how-the-world-s-chip-shortage-isplaying-out-for-stocks

Reuters. (2021, June 2). TSMC says has begun construction at its Arizona chip factory site. https://www.reuters.com/technology/tsmc-says-construction-has-started-arizona-chipfactory-2021-06-01/

Santana-Viera, V., Jimenez, J., Jin, T., \& Espiritu, J. (2014). Implementing factory demand response via onsite renewable energy: a design-of-experiment approach. International Journal of Production Research, 53(23), 7034-7048. https://doi.org/10.1080/00207543.2014.957877

Sectors \& Industries Overview - U.S. Sectors- Fidelity. (2021, August 11). Fidelity.Com. Retrieved August 11, 2021, from https://eresearch.fidelity.com/eresearch/markets_sectors/sectors/sectors_in_market.jhtml Seeking Alpha. (2021, March 9). Lam Research Riding The Rising Tide Of Long-Term Chip Demand. Seeking Alpha. https://seekingalpha.com/article/4453391-lam-research-ridingthe-rising-tide-of-long-term-chip-demand

Shimokawa, K., Jürgens, Ulrich, \& Fujimoto, Takahiro. (1997). Transforming automobile assembly : experience in automation and work organization. Springer. 
Smialek, J., \& Nelson, E. (2021, October 29). The world's top central bankers see supply chain problems prolonging inflation. The New York Times.

https://www.nytimes.com/2021/09/29/business/central-bankers-supply-chainsinflation.html

Staff, R. (2020, May 18). China semiconductor fab SMIC gets $\$ 2.2$ bln investment from gov't funds amid global chip spat. U.S. https://www.reuters.com/article/china-semiconductorsmic-idUSL4N2D019Y

Statista. (2021a, April 23). Semiconductor sales worldwide 2015-2020, by region. https://www.statista.com/statistics/249509/forecast-of-semiconductor-revenue-in-theamericas-since-2006/

Statista. (2021b, October 19). PC GPU shipment share worldwide Q2 2009 - Q2 2021, by vendor. https://www.statista.com/statistics/754557/worldwide-gpu-shipments-marketshare-by-vendor/

Swanson, A., \& Clark, D. (2020, June 17). Lawmakers Push to Invest Billions in Semiconductor Industry to Counter China. The New York Times. https://www.nytimes.com/2020/06/11/business/economy/semiconductors-chips-congresschina.html

TSMC. (2021, January). Form 10-K. Retrieved from NetAdvantage database.

Thomas, P. (2021, October 17). Selling Cars in the Era of the Chip Shortage: Online Chats and No More Haggling. WSJ. https://www.wsj.com/articles/selling-cars-in-the-era-of-thechip-shortage-online-chats-and-no-more-haggling-11634463001

Vance, A. (2008, October 7). A.M.D. to Split Into Two Operations. The New York Times. https://www.nytimes.com/2008/10/07/technology/07chip.html

Villarreal, S., Jimenez, J. A., Jin, T., \& Cabrera-Rios, M. (2013). Designing a Sustainable and Distributed Generation System for Semiconductor Wafer Fabs. IEEE Transactions on Automation Science and Engineering, 10(1), 16-26. https://doi.org/10.1109/tase.2012.2214438

Wang, E. C., \& Huang, W. (2007). Relative efficiency of R\&D activities: A cross-country study accounting for environmental factors in the DEA approach. Research Policy, 36(2), 260 273. https://doi.org/10.1016/j.respol.2006.11.004 
Whalen, J. (2021, June 14). Countries lavish subsidies and perks on semiconductor manufacturers as a global chip war heats up. Washington Post. https://www.washingtonpost.com/technology/2021/06/14/global-subsidiessemiconductors-shortage/

Writer, S. (2021a, January 30). TSMC's bet on global dominance pays off after decades of planning. Nikkei Asia. https://asia.nikkei.com/Business/Tech/Semiconductors/TSMC-sbet-on-global-dominance-pays-off-after-decades-of-planning

Writer, S. (2021b, September 6). Chip prices set to rise into 2022 as TSMC hikes rates. Nikkei Asia. https://asia.nikkei.com/Business/Tech/Semiconductors/Chip-prices-set-to-rise-into2022-as-TSMC-hikes-rates

WSTS Semiconductor Trade Statistics 2019-20. (2020). WSTS. https://www.wsts.org/

Wu, D. (2021, March 31). TSMC to Spend \$100 Billion Over Three Years to Grow Capacity. Bloomberg. https://www.bloomberg.com/news/articles/2021-04-01/tsmc-to-invest-100billion-over-three-years-to-grow-capacity

Wu, J. Z., Chien, C. F., \& Gen, M. (2011). Coordinating strategic outsourcing decisions for semiconductor assembly using a bi-objective genetic algorithm. International Journal of Production Research, 50(1), 235-260. https://doi.org/10.1080/00207543.2011.571457

Wu, W. Y., Tsai, H. J., Cheng, K. Y., \& Lai, M. (2006). Assessment of intellectual capital management in Taiwanese IC design companies: using DEA and the Malmquist productivity index. $R \& D$ Management, 36(5), 531-545. https://doi.org/10.1111/j.14679310.2006.00452.x 